\title{
Ambiguous figure treatments in the art of Salvador Dali
}

GERALD H. FISHER

UNIVERSITY OF NEWCASTLE UPON TYNE, ENGLAND

Attention is drawn to the relatively small number of materials available for use in experimental studies of figureground fluctuations. The use of ambiguity as a formal spatial treatment by artists is described. Details of seven paintings by Salvador Dali into which this treatment has been introduced are described and illustrated.

The figure-ground phenomenon which is basic to understanding of the nature of perceptual organization has provided the subject of a wide variety of experimental studies. Fisher (1966) questioned the assumptions underlying certain of these and has prepared a set of ambiguous figures, the probability of perceiving either alternative aspect of which is the same. The volume of research in this field is such that it is somewhat surprising to learn how few materials are available for use as ambiguous stimuli. The Rubin (1915) figures were used almost exclusively until Boring (1930) pointed out the "wife and mother-inlaw" figure drawn by Hill (1915). Subsequently, Leeper (1935) prepared an ambiguous scene containing a "pirate and rabbit" and Botwinick (1961) devised three "husband and father-in-law" figures, one of which he demonstrated to be equivocal in the sense that each aspect was seen with equal frequency. With the exception of a small sample of other figures such as that depicting a "duck and rabbit" used by Jastrow (1900), the "boys from Syracuse" of Kolers (1964), Tinbergen's (1951) "goose and hawk" figure and Traylor's (1965) "nuns and nudes," these represent the total set of materials available for research on figure-ground fluctuations. In a further communication the author will describe and illustrate a comprehensive set of ambiguous figures which have been used previously, along with other figures newly devised.

The intention of the present paper is to draw attention to the fact that artists, in advance of psychologists, appreciated that changes in the flgural features of spatial forms may be induced by suitable juxtaposition of two-dimensional patterns. So-called "hidden forms" have been used throughout the history of painting; Bonnard, Vuillard, and Escher deliberately introduced ambiguous treatments into their works and the author has recently discovered Beardsley to have used them also-the best example of this latter being an apparently sinister figure overlooking "The Fat Woman," supposed to be a portrait of the wife of Whistler. The artist who has made perhaps the most sustained use of formal ambiguity in painting, however, is Salvador Dali. Much of Dall's life has been spent in Cadaques, a small fishing village on the rocky coast of the Costa Brava. Here the custom of the local fishermen in identifying certain rocks by name impressed itself strongly upon him from boyhood. In his autobiography "The Secret Life of Salvador Dali" (1942) he recalls features of the coastline called the "camel," "eagle," "anvil," "lion's head" and the "dead woman." Dali's preoccupation with the changing figural quality of natural forms is emphasized in his autobiography. Whilst in a fishing boat off Cape Creus one of the fisherman pointed out a rock formation remarking "Look, Senor Salvador, now instead of a camel one would say it had become a rooster" (op cit, p. 304). Describing the way in which features of the rock appeared to change as he was rowed past it, Dali observes 'What had been the camel's head now formed the comb, and the camel's lower lip which was already prominent had lengthened to become the beak. The hump, which had been in the middle of its back, was now all the way back and formed the rooster's tail. As we came nearer, the tips of the anvil had become rounded, and it was exactly like a

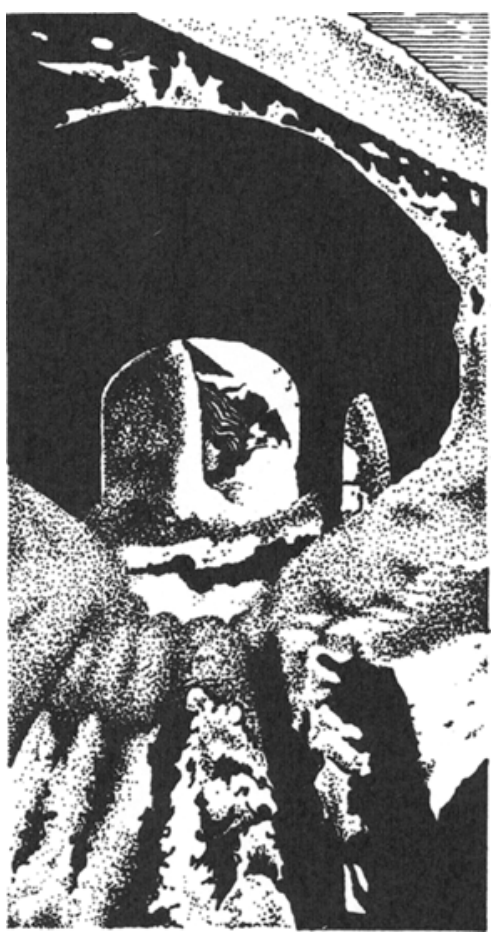

Fig. 1. Detail of the postcard of the Austrian winter scene. 


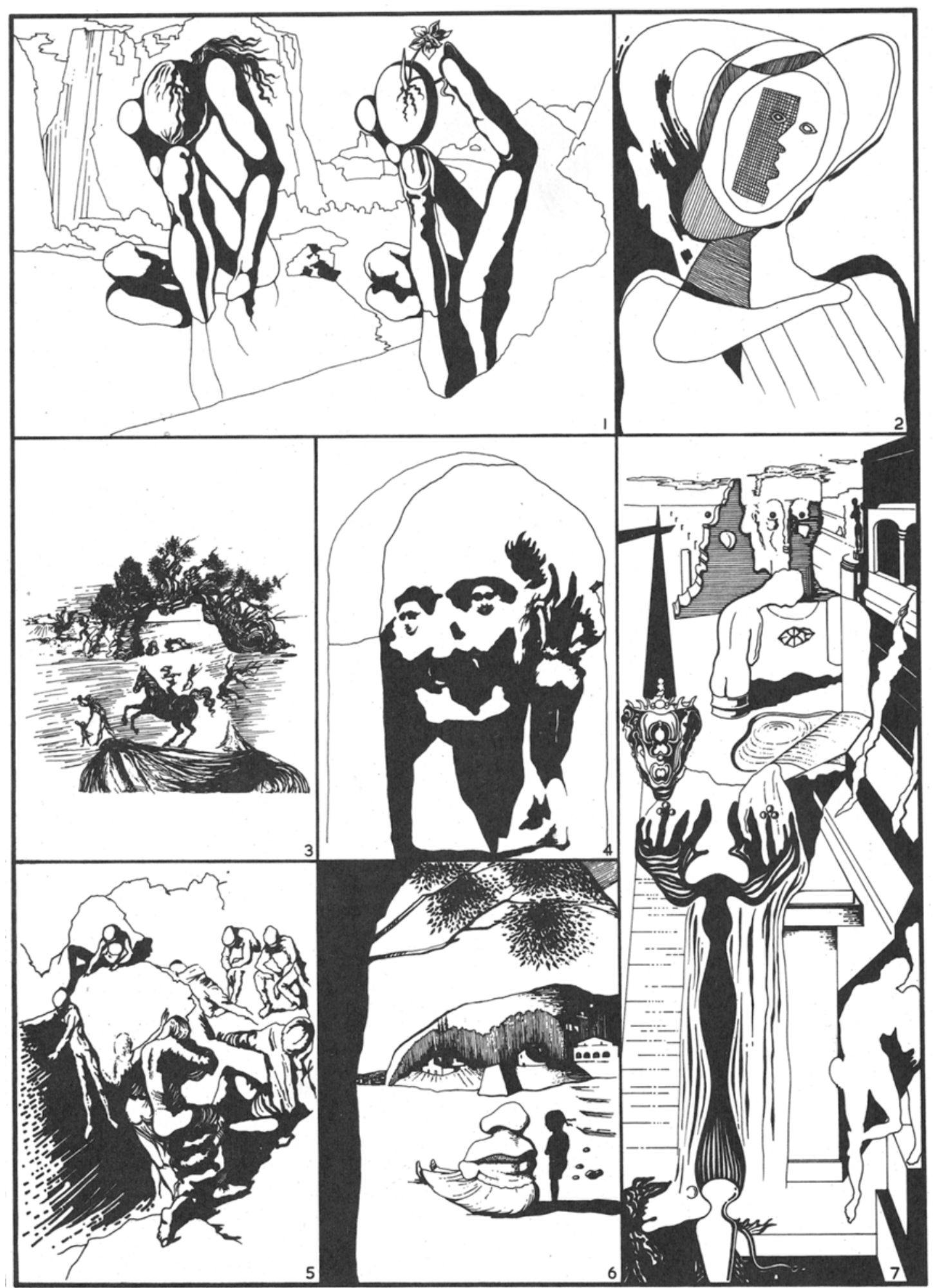

Fig. 2. Detail from: (1) The Metamorphosis of Narcissus, (2) Head of Woman, (3) September, (4) Slave Market with Apparition of the Invisible Bust of Voltaire, (5) The Great Paranoiac, (6) The Three Ages; and (7) The Invisible Man. 
woman's two breasts ... While the fisherman rowed ... one saw these rocks at each monotonous stroke of the oars continually become metamorphosed..." (op cit, pp. 304-305). Such observations as these almost certainly inspired a number of Dali's works in which rock formations appear to change spontaneously into human and animal figures.

Although Dali's preoccupation with duality of theme and its representation was evident in such works as Head of Woman painted in 1927, the first of his paintings to contain a "double image" was The Invisible Man on which he worked throughout the period 19291933. The ambiguity of treatment was labored in this painting, however, and the strong perspective treatment tends to counteract the spontaneous fluidity of the changing forms. It is probably true to say that Dali would have dismissed this work as a mere technical exercise had not Gala, his wife, pointed out to him the ambiguous aspects of the postcard, illustrated in Fig. 1. She noticed that the subject of this Austrian winter scene, a bridge crossing a narrow snow-covered track, appeared to change in appearance in such a way as to resemble the head of Don Quixote. Returning to Cadaques, Dali painted The Great Paranoiac and The Metamorphosis of Narcissus each of which represented significant advances in the development of his artistic technique. Dali continued to be intrigued with the formal ambiguity of the Austrian postcard, however, and modified it in such a way as to represent human figures emerging from a circular doorway, upon reversal of this figure the head of
Voltaire is seen. Dali reproduces this figure frequently in his autobiography and introduces it into a number of works, the most interesting of which is Slave Market with Apparition of the Invisible Bust of Voltaire painted in 1940. Detail of Dall's use of ambiguous-figure treatments is shown in Fig. 2. They should prove to be interesting additions to the repertoire of materials avallable for demonstrations of, and research into, figure-ground fluctuations.

\section{References}

Boring, E. G. A new' ambiguous figure. Amer. J. Psychol., 1930, 42, 444-445.

Botwinick, J. Husband and father-in-law: A reversible figure. Amer. J. Psychol., 1961, 74, 312-313.

Dali, S. The secret life of Salvador Dali. New York: Burton C. Hoffman, Dial Press, 1942.

Fisher, G. H. Materials for experimental studies of ambiguous and embedded figures. Res. Bull. No. 4, Department of Psychology, University of Newcastle upon Tyne, 1966.

Hill. W. E. My wife and my mother-in-law. Puck, 1915, 6th Nov,

Jastrow, J. Fact and fable in psychology. Boston: Houghton Mifflin, 1900.

Kolers, P. A. The boys from Syracuse: Another ambiguous figure. Amer. J. Psychol., 1964, 77, 671-672.

Leeper, R. W. A study of a neglected portion of the field of learning: The development of sensory organization. J. Genet. Psychol., 1935, 46, 41-75.

Rubin, E. Synsoplevede Figurer. Kobenhavn: Glydendalske, 1915.

Tinbergen, N. The study of instinct. Oxford: Clarendon Press, 1951.

Traylor, T. in R. Prelisser. Vision in engineering. Int. Sci. Tech., $1965,46,61-66$.

(Accepted for publication April 7, 1967.) 